\section{In it for the eggs}

\section{T. R. Birkhead}

Female Control: Sexual Selection by Cryptic Female Choice. By William G. Eberhard. Princeton University Press: 1996. Pp. 501. \$85, £60 (hbk); \$29.95, $£ 24$ (pbk).

Females have always had a bad deal in evolutionary speculation. When Darwin first proposed the concept of sexual selection, he imagined two processes: competition between males, and female choice. It was obvious that males fought for access to females, but female choice was far from certain, and some people doubted whether females even have the mental ability to make such choices. It has taken more than a century of painstaking research to show that female choice is a subtle but important part of sexual selection.

Darwin and most subsequent students viewed sexual selection as the acquisition of partners through either fighting or female choice. But in 1970 biologists realized that there was more to sexual selection and that, even after copulation and insemination, competition between males could continue, through the process of sperm competition. Inside the passive female's reproductive tract, the sperm from different males grapple for paternity. Most behavioural ecologists were sexist, and it was more than a decade before the complementary idea of cryptic female choice emerged: that is, that females might also be able to influence the paternity of their offspring. But even this idea was too early for its time, and was generally thought of as barely credible. This was partly because it was far from clear how females could benefit from such choice: on theoretical grounds it seemed unlikely that they could improve the quality of their offspring.

A few years ago, a combination of events changed this perception. Field biologists noticed that it was females rather than males who initiated copulations with different males; theoreticians decided that it was possible for females to gain genetic benefits for their offspring by being fertilized by a particular male after all; and behavioural ecologists began to consider the mechanisms underlying reproductive processes instead of focusing exclusively on the adaptive significance of traits. Suddenly, the field was ripe for a female-centric view of reproductive competition.

William Eberhard's fascinating and scholarly review has finally provided just that. It is a landmark volume that marks a turning point in the study of sexual selection. By drawing our attention to the many different ways in which females may potentially control paternity, the author opens up a whole new field of research.

But the way forward will not be easy, for it is full of traps. As this book reveals, the conflict between the sexes for the control of paternity has resulted in a bewildering array of subtle female anatomical and physiological adaptations, matched by equally remarkable male coevolutionary responses. Disentangling male-caused and female-caused variations in paternity and producing convincing demonstrations of cryptic female choice will be far from straightforward. Nevertheless, the potential rewards are considerable. What is more, acknowledging the existence of cryptic female choice forces us to reconsider the definition of sexual selection: males are not competing for females, they are competing for their ova.

T. R. Birkhead is in the Department of Animal and Plant Sciences, University of Sheffield, Sheffield S10 2TN, UK.

\section{The three faces of Eve's therapist}

\section{Hugh Freeman}

Alter Egos: Multiple Personalities. By David Cohen. Constable: 1996. Pp. 251. £18.95.

SINCE at least 1816 there have been reports of people apparently switching into different identities for periods from a few minutes to several weeks. Robert Louis Stevenson's Dr Jekyll and Mr Hyde illustrated the deep resonance of this possibility in the human mind. Later in the century in Paris, the investigation of hysteria by Jean-Martin Charcot and Pierre Janet, using hypnosis, appeared to show that dissociation of the ego could allow previously hidden aspects of an individual's personality to emerge. But this approach fell into disfavour when it was found that many of the remarkable changes seen in patients were actually induced by the therapists. Dissociation then remained little more than a clinical curiosity until the 1950 s.

David Cohen's main concern is to describe the emergence since then of a new condition - multiple personality disorder - which has taken place almost entirely in North America. It is symbolized by the film The Three Faces of Eve, which was based on an early case and which has influenced patients and therapists in the United States for nearly 40 years. In fact, life seems to imitate art: Cohen reports that alternative personalities "often seem to model their performances on what they have seen on television". The main enthusiast for the condition, Colin Ross, claims that more than six million Americans suffer from the disorder, but in the rest of the world only the Netherlands has recognized its existence to any significant extent.

What has turned the disorder into an important public issue is the belief of those who recognize and treat it that it is caused by abuse in childhood, usually sexual. That most subjects do not remember any such abuse is no problem to the therapists, as by intensive exploration, often under hypnosis, memories of it are 'recovered'. The next step may be for the patient - usually a young woman - to bring a court action against her parents, which may result in the father going to prison.

But there is, in fact, no scientific evidence whatever that multiple personality disorder - if such a condition exists has any connection with abuse in childhood. 'False memory syndrome' is the name now given to the state in which 'memories' of abuse have been induced by the therapist, who then proceeds to 'treat' the alleged disorder. This practice can, of course, be very lucrative.

Cohen describes this imbroglio, but does not acknowledge the overwhelming harm it has done to individuals and families, some of whom will never recover. The issue was thoroughly debated last year in the correspondence columns of the New York Review of Books, although Cohen does not cite this reference.

But Cohen rightly points out that "the fact that memories have been repressed doesn't make them true". He has been unable to find any reliable follow-up studies of the treatment methods used by the therapists. "Ideally, talking through the trauma will pave the way for the creation of a new personality... It is increasingly clear, however, that relatively few cases have such happy endings."

Most likely, multiple personality disorder is a phenomenon that emerges when a suggestible subject comes into contact with a persistent therapist. Cohen suggests that high levels of stress often trigger episodes of dissociation, and that this may be one of the strange ways in which the unconscious speaks. Enthusiasts for the disorder are unlikely to be satisfied with that conclusion.

Alter Egos serves as an introductory account of multiple personality disorder for the nonspecialist reader, although it would have been strengthened by more scientific scepticism.

Hugh Freeman, former editor of the British Journal of Psychiatry, is at 21 Montagu Square, London W1H 1RE, UK.

\section{New Journals}

Next week's issue will contain Nature's annual New Journals review supplement. 